\title{
Social Interaction Distance and Stratification
}

\author{
Wendy Bottero and Kenneth Prandy
}

\section{This is the preprint version of the article that appeared in 2003 in The British Journal of Sociology, 54 (2): 177-197. DOI:10.1080/0007131032000080195, (C) The Authors 2003}

\begin{abstract}
There have been calls from several sources recently for a renewal of class analysis that would encompass social and cultural, as well as economic elements. This paper explores a tradition in stratification that is founded on this idea: relational or social distance approaches to mapping hierarchy and inequality which theorize stratification as a social space. The idea of 'social space' is not treated as a metaphor of hierarchy nor is the nature of the structure determined a priori. Rather, the space is identified by mapping social interactions. Exploring the nature of social space involves mapping the network of social interaction - patterns of friendship, partnership and cultural similarity - which gives rise to relations of social closeness and distance. Differential association has long been seen as the basis of hierarchy, but the usual approach is first to define a structure composed of a set of groups and then to investigate social interaction between them. Social distance approaches reverse this, using patterns of interaction to determine the nature of the structure. Differential association can be seen as a way of defining proximity within a social space, from the distances between social groups, or between social groups and social objects (such as lifestyle items). The paper demonstrates how the very different starting point of social distance approaches also leads to strikingly different theoretical conclusions about the nature of stratification and inequality.
\end{abstract}

Keywords: Social distance, social interaction, stratification, social space

\section{Introduction}

Since stratification refers to hierarchically organized social relationships, stratification theory entails the analysis of structured social inequality in all its aspects: material, social and cultural. However, class analysis, with its focus on material inequality, has dominated stratification theory. Unfortunately, therefore, uncertainties about the state of class analysis and the 'cultural turn' within sociology have resulted in a waning interest in stratification generally. Concerns that class analysis has 'attenuated' and become isolated from the wider concerns of sociology (Crompton 1998; Morris and Scott 1996) have led to calls for a broadening of scope to address issues of cultural identity, gender, race and ethnicity (Bradley 1996; Crompton 1998; Savage 2000). At the same time, from outside stratification theory, there are signs of unease about the way in which accounts of identity and difference have become divorced from accounts of inequality and hierarchy (Alexander 2002; Sivanandan 2001). For some, the calls to broaden class analysis entail a renewed emphasis on status and domination as distinct elements in stratification theory (Scott 1996). However, others see an extended class analysis incorporating these concerns. 
This would be a remarkable transformation, since the reformers reject key components of traditional class theory, such as the centrality of the economic, the distinction between the economic and the cultural, and the notion of class as collectivity. Crompton, for example, advocates 'approaches to social class analysis which, rather than seeking to distance themselves from the status concept, are premised upon the interrelationship of the "economic" and the "social"" (Crompton 1998: 119). A 'renewed" analysis would 'focus on how cultural processes are embedded within specific kinds of socio-economic practices' (Devine and Savage 2000: 193), exploring how 'processes of inequality are produced and reproduced routinely and how this involves both economic and cultural practices' (op. cit.: 196). For class revisionists 'class cultures can be usefully viewed as modes of differentiation rather than as types of collectivity', where 'class' processes operate through individualized distinction rather than in social groupings (Savage 2000: 102).

This project of renewal is so broadly conceived that it can be regarded as a general account of stratification itself, rather than as a specifically 'class' project. Given that the aims of class revisionists entail embracing the idea of inequality as a process of individualized differentiation, emphasize hierarchy over collectivity, and stress the fusion of economic, cultural and symbolic elements in hierarchical differentiation, it is hard to see what remains of 'class' in 'class theory'. Whilst the aims of this project are laudable, they cannot be achieved without transforming class theory into something quite different. There is an existing tradition of stratification theory social distance analysis - which incorporates all these concerns, and yet which starts from a fundamentally different set of premises about the nature of stratification. From this perspective, the structure of stratification is not an influence on patterns of association (in the sense that we might investigate the extent to which economic position affects friendship, or 'class' location influences 'status' relations), rather differential patterns of association and lifestyle constitute the structure of stratification. Starting from this theoretical position, an empirical strategy then follows, to investigate social relations of equality (or equivalence) in order to uncover wider patterns of inequality. This paper explores a number of such social distance approaches and argues that the very different starting point of social distance approaches leads to strikingly different theoretical conclusions about the nature of stratification and inequality.

\section{Social Distance and Social Space}

Perceptions of social structure, as Ossowski points out, 'make considerable use of terms with a spatial connotation', usually without being conscious of their 'metaphorical character' (1963: 7). One key term, 'social distance', has been given a range of emphases, from the psychological to the structural. At one extreme, Bogardus (1925) emphasizes subjective social distance and refers to the social approval or prestige of various social groups, as measured by the perceived level of intimacy (neighbourliness, friendship, marriage and so on) that respondents would find acceptable with individuals from different national, ethnic and religious groups. Similarly, Park distinguishes the degree of intimacy that occurs between individuals from different social groups: 'The degree of . . intimacy measures the influence which each has over the other.' (Park 1950: 257). For Park, who used the term to discuss both class and racial differences, the greater the social distance between individuals, the less they influence each other reciprocally. Park was following Simmel, who used the term to refer to the sphere of social affairs that surrounds each individual, and into which individuals may be permitted to intrude to various degrees: 'The radius of that sphere, so to speak, marks the distance' (Simmel 1906: 452). Here it is the absence 
of closer social contacts, or relations of intimacy, which constitutes social distance.

At the other, structural, extreme, Sorokin (1927) emphasizes not social distance, but social space. However, the two concepts are complementary; distance implies a space of some kind, while a space is defined by the objects that are located in it and the distances between them. These different perspectives open up the possibility of a more precise and consistent account of individual action and social structure, in which actual relationships of intimacy are used to measure the degree of social distance between individuals and groups and thus of the social space in which the distances occur. Far from being no more than a metaphor, interaction distance can be empirically identified by mapping relations of proximity. Looking at patterns of intimate social interaction allows us to conceptualize 'social distance' in terms of both the gap that separates people with dissimilar social and cultural relations, and also the proximity of those with similar social and cultural relationships.

By investigating close association and patterns of cultural and social similarity we can determine social distances, but we can also identify the nature of the social space within which these relations of closeness and distance are located. The central issue, then, is how this social space is to be conceived. The investigation of patterns of differential association has long been a central concern in stratification research. However, social distance approaches offer a very different conceptual and empirical perspective on differential association, and of the stratification order itself, from that of mainstream stratification analysis.

\section{Differential Association and Social Distance}

Conventionally, two research traditions in stratification are identified: a largely American tradition, associated with status prestige hierarchies; and a more European tradition, associated with a discontinuous, relational class structure (Goldthorpe 1980). These distinct traditions nevertheless share a similar approach to differential association. Both look at the extent of unrestricted social ties or social movement between highly aggregated occupational categories that are ordered by different and prior principles, drawn from labour market, status or educational characteristics. That is, a structure is assumed prior to any analysis of differential association; it is a given that the subsequent analysis cannot affect in any fundamental way.

This formula (identifying classes as labour market categories and then investigating patterns of interaction to ascertain their demographic or social identity) derives from Weber, although Weber's theoretical conception saw interaction as the first step

'A 'social class' makes up the totality of those class situations within which individual and generational mobility is easy and typical.' (Weber 1978 [1922]: 302)

Scott argues that methodological practicality has prevented the empirical identification of class boundaries on this basis, but that professional judgement has served as a 'second best solution' (1994: 938). However, there is a distinct research tradition of social distance analysis that has long overcome the methodological problems, and uses patterns of interaction to identify the stratification order. A series of researchers have used patterns of differential association to indicate the nature of the social distances between categories and, thus, the nature of the social space within which the social interaction takes place. Here social interaction distance is taken as a stratification order in its own right. However, such research has tended to eliminate the 
distinction between class and status, or the economic and the cultural, which was once seen as central analytically to conventional stratification theory.

The pioneering work on differential association, by Laumann (Laumann 1966; Laumann 1973; Laumann and Guttman 1966), emerged out of the Warner tradition of research on community association (Warner 1949; Warner 1963). However, rather than drawing on prestige evaluations, Laumann used newly-developed statistical techniques to explore social distance using large data-sets on patterns of interaction. Having defined a stratified social structure as 'one in which there is a tendency for people to confine their intimate social relationships with others of approximately equal rank or status', Laumann and Guttman (1966: 170) measured

'the relative distances among occupations as a function of their degree of associational contiguity, making no assumption about the relative prestige of the occupations.'

This analysis used four different sets of association - the relations between respondents and their friends, their neighbours, their fathers and their fathers-in-law - as the basis for exploring the social distances of finely dis-aggregated occupations (55 categories), and identified a three-dimensional 'space' to fit the interaction distances between occupations.

Laumann and Guttman were the first to identify a stratified social structure from interaction patterns alone and their work provides a basis for later developments. Their account was revolutionary for stratification analysis, since occupations were ordered not by production relations, economic criteria, or perceptions of social standing, but rather by how the occupations were embedded in patterns of social association. However, Laumann and Guttman's methodological innovation was not matched by a corresponding re-evaluation of the theoretical meaning of the stratification order they had identified, and their analytical conclusions remained firmly within the class/status group paradigm. For example, they interpreted the principal dimension of their three-dimensional plot of the social distances between occupations as a 'prestige' ordering, closely related to the Duncan prestige scale of occupations. They also used the patterns of association to group the fine occupational categories into a more limited number of groups or classes. In later work, Laumann (1973) adopted a more limited form of social distance analysis, based only on friendship data (using just 16 occupational categories). This generated a two-dimensional space of distances, with the first dimension again interpreted as 'socio-economic status', and the second dimension roughly identified as corresponding to size of employing establishment.

Early studies following Laumann similarly overlooked the revolutionary potential of social distance analysis, simply using the technique to generate additional information on a stratification order conceptualized in other terms and using groupings generated by expert judgment and prior theoretical argument. Blau and Duncan (1967), for example, used smallest-space analysis to explore the relationships of father-to-son mobility, using 17 aggregated occupational groupings. Their explicit aim was to confirm their existing socio-economic status scheme

'The measure of social distance, inasmuch as it is independent of the rank order of occupations based on average income and education, provides an independent check for validating this rank order.' (Blau and Duncan 1967: 69)

They concluded that the first dimension produced from the analysis 'evidently represents the 
socio-economic status of occupations' (Blau and Duncan 1967: 71). Blau and Duncan's work on social distance amounts to a verification of their existing labour market scheme. A similar approach was used by studies within the European class tradition. Both Hope (1972) and Macdonald (1972), for example, developed a dimensional analysis of father-son mobility tables, in which the first dimension of the analysis produced an ordering of occupations interpreted either as a 'status' ordering (Hope) or as an ordering in terms of 'skill or education' (Macdonald). Both studies also found an orthogonal second dimension, in which farmers and agricultural workers were at a distance from other occupations, which was interpreted as a rural/urban dimension.

The failure on the part of class analysts to address seriously the information on social structure revealed by relational data has been criticized by a number of authors. Very rarely has the distance information contained within mobility tables been used to modify (rather than confirm or explore) the grouping or ordering of class categories (Breiger 1981; Levine 1990; Vanneman 1977). Breiger, for example, argues that the procedures of mobility analysis should be reversed, with the flow data in mobility tables used to determine the nature of class aggregations (Breiger 1981: 578). Similarly, Levine has argued that the stratification order should be identified on 'behavioural criteria' (Levine 1990: 208).

However, such statements of the need to identify occupational hierarchies through interactional criteria have had little impact on conventional stratification research. Although such studies have used distance information to re-order class groupings, they have not affected the classifications and categories more widely used within conventional analysis. The full implications of social distance analysis have only been addressed by writers working outside the mainstream paradigm, who have been less bound by the central theoretical assumptions of that tradition.

\section{Social Interaction Distance Approaches}

Although Laumann and Guttman followed a conventional approach in aggregating occupations into class groupings within the social space, they did not make a clear-cut distinction between a distance continuum and distinct classes

'These groupings should be regarded more as regions in the space - like entrepeneurial vs. salaried, industrial vs. services, and so on - rather than as sharply demarcated class groupings, with well-defined boundaries. There are, of course, differences in regions which may be substantial; but some are differentiated from others only in a matter of degree, often gradually tapering off from one to another.' (Laumann and Guttman 1966: 176)

Social distance approaches fall within a very different theoretical tradition, and one which has been marginalized in stratification research. Whilst such approaches go by a variety of names (associational approaches, dominance scales, relational or exchange approaches, interaction scales, network scales) they all conceive the stratification order in terms of patterns of association. They also share the same emphasis on the finely graded basis of such social distance, and give a similar 'reproductionist' account of how stratified social relations are generated. That is to say, rather than identifying a particular criterion, or set of criteria, such as work and market situation or employment relations, and deriving a stratification structure from them, they concentrate on the way in which a structure of inequality persists over time. 


\section{The Cambridge Stratification Group}

The most wide-ranging approach within the family of social distance measures is the work of the Cambridge stratification group (Prandy 1990; Prandy and Bottero 1998; Prandy and Jones 2001; Stewart et al. 1973; 1980). This work uses a variety of close social relationships to investigate social proximity and distance, on the premise that is it is possible to "extract regularities in the stratification system from patterns of association in non-work situations of respondents characterized by their occupations' (Stewart et al. 1980: 28).

The initial approach (Stewart et al. 1973; Stewart et al. 1980) used the differential association of friends to scale occupations 'in terms of the occupations of persons with whom their incumbents interact' (1980: 28), using finely distinguished occupational categories. Multi-dimensional scaling of the friendship pairs revealed that, whilst up to six dimensions were required to represent the social distances of friendship choices, a single large dimension was by far the most important, and that other dimensions beyond this first one made "no important interpretable contribution' (1980: 43). The first dimension ordering of occupations was then used as a scale of occupations, described as a measure of 'stratification arrangements' (1980: 28).

The original scale used friendship patterns as the basis of the technique, whilst later revisions used the occupations of marriage partners ${ }^{i}$ to update the scale and extend the analysis to the occupations of women (Prandy 1990). The scale has been used, as a measure of stratification arrangements, or 'generalized advantage of lifestyle', to look at the impact of social distance on educational outcomes (Blackburn and Jarman 1993; Blackburn and Marsh 1991; Marsh and Blackburn 1992), ethnic inequality (Blackburn et al. 1997), health and lifestyle (Bartley et al. 1999a; Bartley et al. 1999b; Chandola 1998; Prandy 1999; Sacker et al. 2000), occupational segregation by gender (Blackburn et al. 1999), party and class identification (Prandy 2000) and social mobility (Prandy 1998). Subsequent work has used social relationships such as marriage and affinal kinship, and father-son mobility, to generate historical and cross-national scales, and these scales have been used as the basis for research on historical social mobility (Prandy and Bottero 1998; Prandy and Bottero 2000a; Prandy and Bottero 2000b) and international comparisons of social distance (Prandy and Jones 2001).

This work shows that a number of apparently quite different social relationships (friendship, marriage, affinal and consanguineal kinship) exhibit the same social distance patterns. This is taken as a sign that such social relationships are embedded - and revealed - in a common underlying social hierarchy or ordering. Although the scale is well related to a number of prestige scales, this distance ordering is not regarded as a measure of the status or prestige of occupations. Rather, interaction distance is treated as a social structure in its own right which, whilst reflecting the diverse influences - material, social and cultural - on association, is not reducible to any of them. Instead, the underling hierarchy has been interpreted as a 'scale of shared experience', measuring general, hierarchical 'material and social advantage and ... these are indivisible concepts' (Stewart et al.1980: 28):

'Our conception is one of stratification arrangements that involve differences in generalised advantage (and disadvantage) and hence in lifestyle and in social interaction related to level of advantage.' (Prandy 1990: 635)

This emphasis on the indivisible social, cultural and economic basis of social distance in 
interaction arrangements is reflected in other social distance approaches.

\section{Intergenerational Continuity}

An independent, but closely related approach - 'symmetric scaling of intergenerational continuity’ (SSIC) - was developed by Rytina (Rytina 1992a; Rytina 1992b; Rytina 2000a; Rytina 2000b). Rytina uses intergenerational continuity (the obverse of mobility) to identify associational stratification on the basis that stratification is the lack of movement, or stability, of a structure. The stratification of occupations is revealed by patterns of occupational inheritance

‘. . classes exist only insofar as persistence occurs over generations. Dominance scaling places elements nearer and farther in a mapping of precisely persistence and its logical complement, mobility.' (Rytina 2000b: 9)

Since 'occupational categories are arranged into a hierarchy that constrains inter-generational movement' so, conversely, intergenerational movement (or the lack of it) can be used to rank occupations without any prior assumptions or ordering principles (Rytina 1992b: 1659). The structuring principle is very similar to that which is seen to underlie friendship or marriage; close social contacts define distance: 'Ease and difficulty of intergenerational transition is distance made manifest' (op.cit.: 1678).

The distance information contained in mobility tables (with highly dis-aggregated occupational categories) is used to stratify the occupations of the fathers and sons:

'... locations that are 'near' and 'far' are inferred from frequency of movement. The result, from one angle, is simply the most parsimonious (one dimensional) description of the constraint governing intergenerational stability.' (op.cit.: 1668).

Although this work suggests that a hierarchical gradation captures most of the pattern of mobility in the data, it does also find 'an echo of class' (op.cit.). That is, the distance data suggest some clustering of occupations linked by common mobility separated by gaps which 'record intermediate zones of restricted absorption capacity, as it were, probabilistic barriers to mobility' (op.cit.: 23).

For Rytina, 'the pattern of mobility is the empirical realization of a hierarchical arrangement of occupations' (Rytina 1992a: 1678) and because occupational inheritance refers to the (persistent) differential ability to gain access to advantage, he refers to SSIC as a 'dominance' scale. This is because 'relative success in carving more (and less) attractive paths of least resistance for children reflects the power . . of an occupation' (Rytina 2000a: 1235). In a similar way to the Cambridge group, SSIC is interpreted as a measure of the generalized advantage and resources of the incumbents of particular occupations, as measured by their ability to secure favourable outcomes for their offspring.

\section{Bourdieu and Social Space}

The same stress on the indivisibly social, cultural and economic nature of social distance can be seen in a third social distance tradition: the work of Pierre Bourdieu. Bourdieu's emphasis on the relational nature of social inequality puts him firmly within an associational model of stratification. Yet this aspect of his work (and the consequences of this framework for his empirical research) has been little explored. 
Distinction (Bourdieu 1984 [1979]) is famous as a study of 'class' lifestyles and those advocating a renewal of class analysis are broadly sympathetic to the work of Bourdieu. However, it is clear that Bourdieu is engaged in a form of theorizing which is scarcely recognizable as 'class analysis'

'The conceptual space within which Bourdieu defines class is not that of production, but that of social relations in general. Class divisions are defined not by differing relations to the means of production, but by differing conditions of existence, differing systems of dispositions produced by differential conditioning, and differing endowments of power or capital.' (Brubaker 1985: 761)

Bourdieu uses the relationship between cultural items and occupational groupings (or 'class fractions') to determine the nature of the 'social space' within which the patterning of the relationships are located. This space amounts to an ordering of both the occupational groups and the cultural items, but an ordering given solely by their interrelationships. The 'social space', which Bourdieu describes as a 'space of relationships' (Bourdieu 1985: 725), is made up of the various economic, social and cultural, and symbolic elements of capital and the 'durable dispositions' of habitus (although these are not clearly distinct). That is, the social space is given by the stable preferences and practices (stable in the sense of their routine and widespread occurrence) emerging out of, broadly conceived, economic, cultural and social relations.

The logic of this as an empirical strategy is given by the theoretical assumption that people sharing a similar social position have similar social and lifestyle practices

'On the basis of the knowledge of the space of positions, one can separate out classes, in the logical sense of the word, i.e., sets of agents who occupy similar positions and who, being placed in similar conditions and subjected to similar conditionings, have every likelihood of having similar positions and interests and therefore of producing similar practices and adopting similar stances.' (Bourdieu 1985: 725)

But of course, this logic can be reversed. If we can identify similarity (and difference) in the lifestyles of occupational groups we can map such groups in terms of distance and proximity within an overall social space. This reverse procedure is Bourdieu's approach in Distinction, where the study of cultural items is the study of 'social relations objectified in familiar objects' (Bourdieu 1984 [1979]:77). He interprets the two dimensions of the social space he identifies as representing, on the first dimension, the 'global volume of capital' and, on the second, the relative degree of economic and cultural capital. However, the overall space is defined by the distances between groups given by the similarity (or difference) of their lifestyle as represented by cultural items. What emerges is two orderings, with the cultural items ordering the occupational groups, and the occupational groups ordering the cultural items, but both unified as relations within a space defined by social, cultural and economic processes.

Bourdieu's 'classes' have sometimes been called 'status groups' (Brubaker 1985), but this is doubly misleading. It retains an opposition that Bourdieu rejected - he argued, for example, that 'symbolic capital, commonly called prestige, reputation, renown, etc., . . is the form in which the different forms of capital are perceived and recognized as legitimate' (Bourdieu, 1985: 724) - and it overlooks his view that 'the social classes that can be separated out in social space ... do not exist as real groups (op.cit.: 725). The entities are best seen as locations within this overall 
social space and can only be very loosely regarded as 'groups' since Bourdieu sees their boundaries as being like 'a flame whose edges are in constant movement, oscillating around a line or surface' (Bourdieu 1987: 13).

Bourdieu makes an explicit link between issues of taste, in terms of cultural and lifestyle preferences, and taste more widely conceived, in terms of interaction choices:

'Taste [. . . ] functions as a sort of social orientation, a 'sense of one's place', guides the occupants of a given place in social space towards the social positions adjusted to their properties, and towards the practices of goods which befit the occupants of that position.' (Bourdieu 1984 [1979]: 466-7)

Bourdieu's argument of a commonality between different forms of social relations (choice of cultural items, choice of friends, choice of marriage partners) implies that the space of social relations is a generalized structure of advantage (social, economic and cultural), in which different distance patterns are governed by the same underlying principles

'... the concordance between a socially classified person and the socially classified things or persons which 'suit' him is represented by all acts of co-option in fellow-feeling, friendship or love which lead to lasting relations, socially sanctioned or not. . . Taste is what brings things and people that go together.' (Bourdieu 1984 [1979]: 241)

This supports his theoretical argument, but is not empirically addressed. However, as we have previously argued, other research on social distance suggests that the distance patterns of a variety of social relationships are remarkably similar in structure. The implication of such findings for the theorization of stratification arrangements are potentially very far-reaching.

\section{Theorizing Distance}

Although social distance studies show some variation in techniques of analysis, and in the types of differential association studied, they make remarkably similar theoretical claims and can be regarded as a 'family' of approaches. The distinctive nature of these theoretical claims arises directly out of the centrality of interaction patterns to such approaches. The central issue relating to them is the interpretation of the social space that is generated by the analysis of interaction patterns. What is the nature of the social ordering that is revealed by such analysis?

\section{Dimensionality and Social Space}

Often, more than one dimension is required to represent relational distances, and authors have given varying accounts of what these dimensions represent. In conventional approaches, the first or strongest dimension has been equated with status or prestige, whilst additional dimensions have been variously, and tentatively, related to private/public, rural/urban or entrepreneurial/bureaucratic divides. However, the more disaggregated technique of social distance approaches suggest that the various dimensions generated by statistical analysis should not be equated with the multiple dimensions of stratification theory. Social distance approaches which use a large number of occupational categories treat only the first or most important dimension as a social ordering.

Analyses using a limited number of occupational categories require fewer dimensions to 'fit' the social relations than those using more disaggregated occupational units. However, the greater the 
number of occupational units, the harder it is to give additional dimensions a straightforward interpretation. Such dimensions cannot be neatly mapped as distinct social divisions (Prandy and Bottero 1998). For example, part of the added complexity that greater occupational detail reveals is geographical, rather than social distance. Farmers and/or agricultural workers often appear on a separate dimension to other groups, whilst in historical samples, miners and fishermen also appear on a separate dimension (Bakker 1993; Haller 1981; Hope 1972; Macdonald 1972; Mitchell and Critchley 1985; Prandy and Bottero 1998; Prandy and Jones 2001). This reflects the geographical concentration and isolation of such groups and, since geographical distance inevitably constrains social interaction, such physical distance appears as an overlay on social distance. There may be many such (geographically) spatial separations, and the multiple dimensions generated by them cannot be equated with social orderings (although they clearly reflect aspects of distance). Although two occupations may, by patterns of social contact, appear to be socially, because geographically, distant, they can still be close to each other in a particular dimension because of the similar relationships they have to the set of other occupational groups (Prandy and Bottero 1998).

Recent developments in methods of analysis mean that it is now possible to model specific bases for interaction such as geographical location or, for example, the association between husbands' and wives' occupations that result from their running a joint enterprise. This tends to clarify the nature of the first, major dimension of the space that is taken in social distance approaches as a generalized social ordering. They have not, with the exception of Bourdieu, interpreted the other dimensions of the space.

\section{Common Structure}

One of the most important commonalities across social distance approaches is the striking similarity in the nature of the social distance revealed by quite different sets of social relationships. The implication is that the same stratification ordering constrains a variety of social relations and practices and that, conversely, a range of social relations can be used to identify this constraining structure. The patterning of such different sets of relationships as friendship, marriage and family connection all indicate a very similar social hierarchy. There is considerable evidence that whichever of a range of social relationships is chosen, the underlying structure that is revealed is very much the same. ${ }^{\text {ii }}$ The fact that similar underlying hierarchies are embedded - and revealed - in quite different social relationships has important theoretical and empirical consequences.

Although some relationships are more strongly constrained by hierarchy than others (the correlation between the occupations of friends is stronger than that between those of spouses, spouses are more strongly associated than are parents and children), statistical distance techniques have proved robust in the face of weaker associations and capable of revealing an underlying pattern. Since they reveal same pattern, the privileging of one set of social relations over another as more central or important in social distance processes is unnecessary. However, the fact of commonality has to be taken into account when theorizing the resultant structure. Grusky and Van Rompaey, for example, have criticized Rytina's focus on inter-generational continuity:

'Unless we believe that parent-child ties are the only 'social glue' holding classes together, there is no reason to give precedence to the relationships in a mobility table 
relative to those represented in tables of assortative mating, residential segregation and the like.' (Grusky and van Rompaey 1992: 1723)

Their argument is that mobility is not an 'exhaustive measure of relational processes' (1992: 1723). However, the similarity of the structure revealed by intergenerational continuity to that revealed by marriage or friendship (Rytina 2000b) suggests that the choice of one set of social relations to measure distance is less of a problem than the idea that there can be a 'best set' of social relations to theorize it. What are the theoretical consequences of a structure that is embedded and revealed in diverse social relations?

It is apparent that a number of writers working with different social interaction distance approaches have drawn the same theoretical conclusions from similarity of structure. The first conclusion is that, since the same underlying structure is revealed in different social relations, it suggests that what is being revealed is a distinct and sui generis quantity - social distance as a structural feature.

Following from this, the second conclusion is about the implication of there being a structure of social distance that is embedded in diverse social relations. This is that social relations do not merely reflect social distance, they are also a key element in the process of reproducing it. Bourdieu, for example, suggests that homogamy and cultural tastes are governed in the same fashion, arguing that 'the structure of the circuit of matrimonial exchange tends to reproduce the structure of the social space [of cultural items] as described here' (Bourdieu 1984 [1979]: 241). The implication is that the study of the relations between cultural items and occupational groups reveals the same structure of social distance that underpins the patterning of social relations between occupational groups, as indicated, for example, by patterns of homogamy. Of course, this is also a conclusion about the diverse ways in which social distance is reproduced and generated by the choice of cultural items, partners and friends

'Taste is a match-maker; it marries colours and also people, who make 'well-matched couples', initially in regard to taste. ... This spontaneous decoding of one habitus by another is the basis of the immediate affinities which orient social encounters, discouraging socially discordant relationships, encouraging well-matched relationships, without those operations ever having to be formulated other than in the socially innocent language of likes and dislikes.' (Bourdieu 1984 [1979]: 243)

\section{The Nature of Social Space}

Social distance measures are well related to scales of status and prestige, and have often been interpreted as prestige orderings. However, social distance cannot be reduced to issues of prestige or status. Clearly, differential association is affected by perceptions of the relative prestige or status of the individuals involved. Yet close social relationships are governed by factors that go beyond cognitive prestige judgments. Distance measures are not composite measures in the same sense as prestige/status scales, since they map actual social relations of intimacy and similarity. They also tap into the social resources that underpin such interactions, and this is reflected in the fact that they are also well related to class schemes. Differential association is, of course, related to labour market advantage, and to the various economic and material resources to which individuals have access. Yet, again, social distance is not a measure of economic advantage or of labour market circumstances as such, since relationships of intimacy are affected not just by economic advantage or labour market position, but also by 
issues of cultural background, social networks, contiguity and opportunity of access, and so forth.

In effect, what social distance measures capture is precisely that: distance in social interactions. Distance is governed by a variety of social, cultural and economic processes and can be regarded as a reflection of the generalized advantage and disadvantage which underpin such interactions. The theoretical basis of the measures is, as we have indicated, an emphasis on the reproduction of inequality; that is, that those with greater advantage will act in such a way as to maintain their position. They can do so by associating with others at a similar level, by engaging in cultural practices that are symbolic of their position and by seeking to pass on their position to their offspring. Although one could associate each of these with the approaches of the Cambridge group, Bourdieu and Rytina respectively, this is purely a matter of emphasis and all three approaches would see them as aspects of a single process. Advantage is conferred by command over resources of various kinds, including those that would conventionally come under the heading of class; some of these can be converted into other resources and many of them are strongly inter-related. In this sense, stratification is 'multi-dimensional', but this should not be confused with the more strictly defined, orthogonal, independent dimensions of statistical analysis. What the space and the distances within it reveal is the way in which combinations of particular resources are socially aggregated into generalised advantage (Prandy 2002:1568).

\section{Group Boundaries and Social Closure}

Social distance models see social distance as reproduced in such simple actions as our choice of friends and marriage partners, or our cultural tastes and preferences. This emphasis on the variety of social relationships which generate social distance has implications for some of the central assumptions of stratification theory. In particular, the dominant emphasis in conventional stratification theory on social exclusion, social closure and conflict, needs reassessment.

The related notions of boundaries, social closure and distinct groups within the stratification order have been central to the key conceptual paradigm in studies of inequality and stratification. The identification of such groups, analytically and demographically, has become the 'first fact' of stratification analysis. The stress on social mobility as a 'class' concern reflects this, since high levels of occupational inheritance are assumed to affect class boundaries and formation. These boundaries, however, remain those of pre-determined groupings.

The same emphasis on boundaries between pre-defined groups can be seen in research on other forms of differential association and in the 'status' tradition. The extensive body of research on assortative marriage, for example, whilst theoretically and empirically less sophisticated (Kalmijn 1998), explores differential marital association in the same way as research on mobility, using social ties to establish the extent of boundaries and social closure in the occupational structure.

'... interaction between social groups provides a fundamental way to describe the group boundaries that make up the social structure. Because marriage is an intimate and often long-term relationship, intermarriage or heterogamy not only reveals the existence of interaction across group boundaries, it also shows that members of different groups accept each other as social equals. Intermarriage can thus be regarded as an intimate link 
between social groups; conversely, endogamy or homogamy can be regarded as a form of group closure.' (Kalmijn 1998: 396)

Even in critiques of the 'class' paradigm, the emphasis on boundaries and group conflict remains. Grusky and Sorenson (1998), for example, argue for dis-aggregated occupational analysis, suggesting that occupations more properly bear the properties that have been attributed to classes. They see these properties as being the collective competition for advantage, via organised struggles and conflict.

However, accounts of stratification must not be abridged to processes of collective struggle and conflict alone, and it is important that differential association be conceived more broadly than movement across group boundaries. The methods and assumptions of conventional mobility analysis should not be the paradigm for all stratification processes. Because social distance approaches look at a wider variety of social relations they have a different theoretical emphasis, with less stress on boundaries and group struggles. As Barnes (1992: 262) points out, one of the faults of sociological theory is that it 'sometimes takes for granted the existence of ... groups as part of a "given" social order'. He claims, though, that sociological theory is increasingly coming to recognize that, like other aspects of the social order, 'boundary maintenance takes work'.

It is certainly possible to find examples of such boundary maintenance, or, more properly, attempts at boundary construction, in the not-too-distant past. The division between staff and works, with its associated symbolic (e.g. separate works canteens) and material (e.g. pension arrangements) aspects is an obvious one in the employment sphere (Wedderburn 1974). Council housing, where in at least one instance the boundary was given physical expression (Collison 1963), is equally obvious in the area of residential association. However, the declining importance of both these boundaries shows that there are other processes at work that serve to bring about such decay.

Clearly, questions of assent or acceptance and challenge or rejection are significant in this regard. It has often been argued that gradational scales favour assumptions of 'openness' and of normative assent to hierarchy, and this claim has been used to justify the use of the alternative relational 'class' approach (Crompton 1993; Goldthorpe 1980; Marshall 1997; Scott 1996). However, even if assumptions of consensus are embedded in the gradational prestige scales of the American theoretical tradition, such an assumption is not intrinsic to social distance scales. Ironically, the use of class groupings may actually weaken the arguments for which they are being deployed: in mobility research, for example, there is evidence that they lead to an overestimation of the extent of fluidity (Hout and Hauser 1992; Kelley 1990) and that gradational social distance schemes in fact uncover greater levels of social reproduction (Prandy 1998; Prandy and Bottero 2000b; Rytina 2000a; Rytina 2000b). There is nothing in social distance approaches which is inimical to the theorization and identification of groups. Indeed a number of the approaches discussed have used distance techniques to attempt to identify distinct groups (Laumann and Guttman 1966; Rytina 2000b).

Just as social distance approaches do not involve any necessary assumption of consensus, so equally they avoid assuming that the reproduction of social hierarchy is only associated with processes of conflict or competition, subordination and exclusion. Such reproduction must also be considered in relation to non-conflictual or positional processes, for which the more general term 'social distance' is better employed. For example, the choice of friends or marriage partners 
may be in part a competitive process in which higher level partners are universally valued and people generally wish to 'marry up' (and avoid 'marrying down') - the 'prestige' hypothesis. Equally, though, it is a process in which people wish to partner with status equals, preferring to marry those individuals whose status position, tastes and lifestyle are similar to their own - the 'like me' hypothesis (Kalmijn 1994). Similarly, although part of the explanation of social mobility may be a general desire (for one's children) to achieve the more desirable occupational positions, there is also a conservative effect that operates through habituation, differential knowledge of opportunities, and risk aversion.

The processes that generate assortative marriage or social mobility/reproduction are, at least in part, determined by preference and habituation, rather than by exclusion alone. Within this model, no barriers need exist in the social order, yet social contact or movement can still be limited by social and cultural dissimilarity. Processes as simple as the lack of ease and comfort in social interaction may prevent the formation of close relationships between socially distant individuals, without any requirement for strategies limiting contact or denying access to privileged circles. Differences in taste and manners, and lack of ease in interaction may be described as social exclusion, but they are more properly understood as social distance. Such differences may be employed in strategies of exclusion and in the erection of social barriers, but it is also important to recognize the way in which social distance is routinely and unintentionally reproduced, through mutuality and the most everyday of social actions. Whether we wish to or not, we all routinely reproduce hierarchy and social distance 'behind our backs' and it is important to distinguish such activities from explicit actions of closure.

Conceptualization in terms of competitive class groupings with distinct boundaries is not essential to an understanding of how inequality is reproduced, since gradational social distance can also explain such processes. On the contrary, in fact, some notion of prior social distance is required in order to theorize the formation of distinct group boundaries or exclusionary strategies. This is because some account of positional difference and social distance is required to explain how distinct groups form and mobilize social and cultural resources in the first place. So, accounts of group boundaries must sit within a prior understanding of social distance. Social distance approaches conceptualize boundaries and closed groupings as a special case of more general relationships (or the lack of them) in social space. Issues of group formation and exclusionary strategies are important elements in any account of stratification, but the existence of groups should not be taken as the exemplar of stratification processes. The role of group processes in stratification has to be theorized from within the concept of social distance.

\section{Conclusion}

There have been calls from several sources recently for a renewal of class analysis that would encompass social and cultural, as well as economic elements. However, as we have suggested in this paper, such an emphasis results in a radically different approach to stratification theory. Social distance approaches look at the way in which hierarchy and inequality are routinely reproduced through social interaction, and see such reproduction as the result of the indivisible influence of economic, cultural and social resources on everyday social life.

As a result, social interaction distance approaches represent a very different theoretical and empirical tradition within stratification research. They make no prior assumptions about the nature of the social order, or of the position of groups within it, instead using patterns of close 
social interaction to map relations of distance within an overall social space. These relations of social distance are conceived of as a sui generis social ordering of generalized advantage, as it affects differential association. Social distance approaches draw on a variety of social relationships and this plurality leads to a very different theoretical account of the nature and reproduction of hierarchy. Boundaries, conflict and social exclusion are not theorized as the first fact of stratification, but instead are placed within a wider model of social distance processes. Social distance is not just reflected in social relationships, such as friendship, marriage, cultural distinction and intergenerational continuity, it is also generated and reproduced in them. The central argument of social distance approaches is that if such different sets of relationships reproduce the same social ordering, then we need to rethink the nature of inequality and how it is structured and maintained. In particular, it is important to understand the interrelationships of economic, social and cultural elements.

\author{
Wendy Bottero \\ University of Southampton \\ Ken Prandy \\ Cardiff University
}




\section{Bibliography}

Alexander, C. 2002 'Beyond black: rethinking the colour/culture divide', Ethnic and Racial Studies 25(4): 552-71.

Bakker, B. F. M. 1993 ' A new measure of social status for men and women: the social distance scale', Netherlands Journal of Social Sciences 29(2): 113-129.

Barnes, B. 1992 'Status groups and collective action', Sociology 26(2): 259-270.

Bartley, M., Sacker, A., Firth, D. and Fitzpatrick, R. 1999a 'Social position, social roles and women's health in England: changing relationships 1984-1993', Social Science and Medicine 48(1): 99-115.

- 1999b 'Understanding social variation in cardiovascular risk factors in women and men: the advantages of theoretically based measures', Social Science and Medicine 49(6): 831-46.

Blackburn, R. M., Dale, A. and Jarman, J. 1997 'Ethnic differences in attainment in education, occupation and life-style', in V. Karn (ed.) Ethnicity in the 1991 Census: Volume Four, London: ONS/Stationery Office.

Blackburn, R. M. and Jarman, J. 1993 'Changing inequalities in access to British universities', ORE 19(2): 197-215.

Blackburn, R. M., Jarman, J. and Brooks, B. 1999 'The relation between gender inequality and occupational segregation in 32 Countries', Cambridge Studies in Social Research 2:

Sociological Research Group, University of Cambridge

Blackburn, R. M. and Marsh, C. 1991 'Education and social class: revisiting the 1944 Education Act with fixed marginals', British Journal of Sociology 42(4): 507-36.

Blau, P. M. and Duncan, O. D. 1967 The American Occupational Structure, New York: Wiley. Bogardus, E. S. 1925 'Measuring social distance', Journal of Applied Sociology 9: 299-308.

Bourdieu, P. 1984 [1979] Distinction: A Social Critique of the Judgement of Taste, London:

Routledge and Kegan Paul.

— 1985 'The social space and the genesis of groups', Theory and Society 14(6): 723-44.

- 1987 'What makes a social class? On the theoretical and practical existence of groups',

Berkeley Journal of Sociology 32: 1-17.

Bradley, H. 1996 Fractured Identities: Changing Patterns of Inequality, Cambridge; Cambridge, MA: Polity Press.

Breiger, R. L. 1981 'The social class structure of occupational mobility', American Journal of Sociology 87(3): 578-611.

Brubaker, R. 1985 'Rethinking classical theory: the sociological vision of Pierre Bourdieu', Theory and Society 14(6): 745-75.

Chandola, T. 1998 'Social inequality in coronary heart disease: a comparison of occupational classifications', Social Science and Medicine 47(4): 523-33.

Collison, P. 1963 The Cutteslowe Walls: A Study in Social Class, London: Faber.

Crompton, R. 1993 Class and Stratification: An Introduction to Current Debates: Cambridge: Polity Press.

- 1998 Class and Stratification: An introduction to current debates, 2nd Edition: Cambridge:

Polity Press.

Devine, F. and Savage, M. 2000 'Conclusion: Renewing class analysis', in R. Crompton, F. Devine, M. Savage and J. Scott (eds) Renewing Class Analysis, Oxford: Blackwell. 
Goldthorpe, J. H. 1980 Social Mobility and Class Structure in Modern Britain, Oxford: Oxford University Press.

Grusky, D. B. and Sörensen, J. B. 1998 'Can class analysis be salvaged?', American Journal of Sociology 103(5): 1187-234.

Grusky, D. B. and van Rompaey, S. E. 1992 'The vertical scaling of occupations: some cautionary comments and reflections', American Journal of Sociology 97(6): 1712-28.

Haller, M. 1981 'Marriage, women, and social stratification: a theoretical critique', American Journal of Sociology 86(4): 766-95.

Hope, K. 1972 'Quantifying constraints on social mobility: the latent hierarchies of a contingency table', in K. Hope (ed.) The Analysis of Social Mobility: Methods and Approaches, Oxford: Clarendon Press.

Hout, M. 1982 'The association between husbands' and wives' occupations in two-earner families', American Journal of Sociology 88(2): 397-409.

Hout, M. and Hauser, R. M. 1992 'Symmetry and hierarchy in social mobility: a methodological analysis of the CASMIN model of class mobility', European Sociological Review 8(3): 239-66.

Kalmijn, M. 1994 'Assortative mating by cultural and economic occupational status', American Journal of Sociology 100(2): 422-52.

- 1998 'Intermarriage and homogamy: causes, patterns, trends', Annual Review of Sociology 24: 395-421.

Kelley, J. 1990 'The failure of a paradigm: log-linear models of social mobility', in J. Clark, C. Modgil and S. Modgil (eds) John H. Goldthorpe: Consensus and Controversy, London: Falmer Press.

Laumann, E. O. 1966 Prestige and Association In An Urban Community: An Analysis of An Urban Stratification System, Indianapolis: Bobbs-Merrill Inc.

- 1973 Bonds of Pluralism: The Form and Substance of Urban Social Networks, New York: John Wiley and Sons.

Laumann, E. O. and Guttman, L. 1966 'The relative associational contiguity of occupations in an urban setting', American Sociological Review 31: 169-78.

Levine, J. H. 1990 'Measuring occupational stratification', in R. L. Breiger (ed.) Social Mobility and Social Structure, Cambridge: Cambridge University Press.

Macdonald, K. I. 1972 'MDSCAL and distances between socio-economic groups', in K. Hope (ed.) The Analysis of Social Mobility: Methods and approaches, Oxford: Clarendon Press.

Marsh, C. and Blackburn, R. M. 1992 'Class differences in access to higher education', in R.

Burrows and C. Marsh (eds) Consumption and Class, Divisions and Change, London:

Macmillan.

Marshall, G. 1997 Repositioning Class, London: Sage.

Mitchell, J. C. and Critchley, F. 1985 'Configurational similarity in three class contexts in British society', Sociology 19(1): 72-92.

Morris, L. and Scott, J. 1996 'The attenuation of class analysis: Some comments on G.

Marshall, S. Roberts and C. Burgoyne 'Social Class and the Underclass in Britain in the USA", British Journal of Sociology 47(1): 45-55.

Ossowski, S. 1963 Class Structure in the Social Consciousness, London: Routledge and Kegan Paul.

Park, R. E. 1950 Race and Culture, New York: The Free Press. 
Prandy, K. 1990 'The revised Cambridge scale of occupations', Sociology 24(4): 629-55.

- 1998 'Class and continuity in social reproduction: an empirical investigation', Sociological Review 46(2): 340-64.

- 1999 'Class, stratification and inequalities in health: a comparison of the Registrar-General's Social Classes and the Cambridge Scale', Sociology of Health and Illness 21(4): 466-84. - 2000 'Class, the stratification order and party identification', British Journal of Political Science 30(Part 2): 237-58.

- 2002 'Ideal types, stereotypes and classes', British Journal of Sociology 53(4): 583-602.. Prandy, K. and Bottero, W. 1998 'The use of marriage data to measure the social order in nineteenth-century Britain', Sociological Research Online 3(1).

- 2000a 'Reproduction within and between generations: The example of nineteenth-century Britain', Historical Methods 33(1): 4-15.

- 2000b 'Social reproduction and mobility in Britain and Ireland in the nineteenth and early twentieth centuries', Sociology 34(2): 265-81.

Prandy, K. and Jones, F. L. 2001 'An international comparative analysis of marriage patterns and social stratification', International Journal of Sociology and Social Policy 21(4/5/6): 165-83. Rytina, S. 1992a 'Response to Hauser and Logan and Grusky and Van Rompaey', American Journal of Sociology 97(6): 1729-48.

- 1992b 'Scaling the intergenerational continuity of occupations: is occupational inheritance ascriptive after all?', American Journal of Sociology 97(6): 1658-88.

- 2000a 'Is occupational mobility declining in the United States?', Social Forces 78(4):

1227-76.

- 2000b 'A keynote of hierarchy, an echo of class: the fine texture of mobility in England and Wales' Fifth International Conference on Logic and Methodology, Cologne.

Sacker, A., Firth, D., Fitzpatrick, R., Lynch, K. and Bartley, M. 2000 'Comparing health inequality in men and women: prospective study of mortality 1986- 96', British Medical Journal 320(7245): 1303-07.

Savage, M. 2000 Class Analysis and Social Transformation, Buckingham: Open University. Scott, J. (1994) 'Class Analysis - Back to the Future' in Sociology 28 (4): 933-942.

Scott, J. (1996) Stratification and Power: Structures of Class, Status and Command, Cambridge: Polity.

Simmel, G. 1906 'The sociology of secrecy and of secret societies', American Journal of Sociology 11(4): 441-98.

Sivanandan, A. 2001 'Poverty is the new black', Race and Class 43(2): 1-5.

Sorokin, P. A. 1927 Social Mobility, New York and London: Harper and Brothers.

Stewart, A., Prandy, K. and Blackburn, R. M. 1973 'Measuring the class structure', Nature 245(5426): 415-17.

- 1980 Social Stratification and Occupations, London: Macmillan.

Vanneman, R. 1977 'The occupational composition of American classes: Results from cluster analysis', American Journal of Sociology 82(4): 783-807.

Warner, W. L. 1949 Social Class in America: A manual of procedure for the measurement of social status, New York: Harper and Row.

- 1963 Yankee City, New Haven: Yale University Press.

Weber, M. 1978 [1922] Economy and Society: An outline of interpretive sociology, Berkeley; London: University of California Press. 
Wedderburn, D. (ed.) 1974 Poverty, Inequality and Class Structure, Cambridge: Cambridge University Press. 


\section{Notes}

i. Bakker (1993) also used marriage patterns to develop a social distance scale for the Netherlands; however, he reported only a limited number of analyses using the resultant scale.

ii. Using data from the Oxford Social Mobility Study, Mitchell and Critchley looked at the hierarchical ordering produced by a multi-dimensional scaling of the occupations held in three sets of relations: between male respondents and their fathers, fathers-in-law, and (male) spare-time associates. They found very high correlations between the hierarchies revealed: their conclusion was that 'the basic structure is essentially the same in all three cases' (Mitchell and Critchley 1985: 72). Hout, comparing the loglinear distance models of husband-wife and father-son associations, found 'striking' similarities, and argued that the 'results support the interpretation of the two associations as indicators of a single underlying status hierarchy' (Hout 1982: 406). Other studies have found a very close relationship between the structures revealed by patterns of friendship and marriage (Prandy 1990; Prandy and Jones 2001; Stewart et al. 1980). Historical samples show the same phenomenon, of a similar structure revealed by both affinal and consanguineal kinship and by intergenerational mobility. Correspondence analysis of the pairings of the occupations of grooms, fathers and fathers-in-law drawn from nineteenth-century marriage records revealed a common ordering: 'the three analyses can be regarded with a very high degree of certainty as different estimates of essentially the same structure' (Prandy and Bottero 1998). Similarly, Rytina found his scale of intergenerational continuity, was highly correlated to the Cambridge scale, generated from friendship and marriage patterns (Rytina 2000b). 